\title{
Análise da alocação de investimentos de empresas privadas e públicas no setor elétrico brasileiro
}

Denizart do Rosário Almeida e Andréa Costa Amâncio Negrão

\section{Introdução}

Até a metade da década de 1990, o modelo institucional adotado pelo setor elétrico brasileiro caracterizava-se por ser estatal, regulado e verticalizado, com as empresas podendo atuar simultaneamente como geradoras, transmissoras e distribuidoras de energia elétrica.

A escassez de crédito mundial, as limitações financeiras do Estado e as pressões de toda ordem por mais eficiência por parte das empresas estatais contribuíram para a adoção de um novo modelo regulatório, que passou a viger a partir da segunda metade da década de 90.

O governo não mais exerceria o papel de principal investidor, passando a compartilhar com a iniciativa privada a responsabilidade pela expansão do sistema. Ao Estado caberia regular as atividades de mercado, equilibrando os interesses entre consumidores (desejosos por adquirir serviço de qualidade a preços baixos) e empresas (desejosas por obter retorno justo sobre os 
investimentos realizados), de modo a contribuir para a criação de um ambiente de eficiência econômica.

Recentemente, em 2003, o atual governo decidiu rever as bases do modelo institucional do setor elétrico. $\mathrm{O}$ forte contingenciamento ocorrido entre junho de 2001 e fevereiro de 2002 (agravado pela insuficiência de investimentos na expansão do sistema), o crescente endividamento das concessionárias de energia elétrica (dificultando a continuidade e qualidade na prestação do serviço) e as dificuldades na implementação da modicidade tarifária para os consumidores e universalização do acesso dos serviços de energia elétrica destacaram a necessidade de um rearranjo regulatório.

No documento "Proposta de Modelo Institucional do Setor Elétrico", divulgado pelo Ministério de Minas e Energia em dezembro de 2003, o governo deixa claro que o desafio seria estabelecer um marco regulatório que garanta os incentivos adequados aos novos investimentos, preservando os interesses dos diversos agentes do setor elétrico e consumidores, de modo a promover o bem-estar e a eficiência econômica.

Nesse contexto, este trabalho objetiva analisar a alocação de investimentos das empresas públicas e privadas no setor elétrico brasileiro em tempos recentes (19952005), com o intuito de avaliar os fatores determinantes do crescimento sustentado do setor face ao novo ambiente regulatório.

Para tanto, está dividido em quatro seções, além desta introdução. A primeira apresenta uma síntese do marco teórico sobre a questão da eficiência econômica (mais especificamente alocativa e dinâmica), destacando o papel do Estado como interventor direto e agente regulador na promoção desse objetivo; a segunda apresenta a evolução da eficiência alocativa no período analisado, tomando como base o comportamento das tarifas médias de energia elétrica; a terceira apresenta a evolução de indicadores e a eficiência dinâmica baseadas nas metodologias de Melo e Rodrigues Jr. (1998) e Steindl (1983), com o intuito de examinar a capacidade de investimentos de curto e longo prazos das concessionárias públicas e privadas do setor elétrico brasileiro. A última seção apresenta as conclusões do presente trabalho.

\section{Regulação econômica e economia da empresa pública: o arcabouço teórico sobre eficiência alocativa e dinâmica}

O conceito de eficiência econômica está relacionado à limitação de recursos e às ilimitáveis necessidades sociais. Nesse sentido, seu significado está associado a escolhas socialmente eficazes, que reproduzem as escalas de preferência da sociedade por determinadas combinações de bens e serviços finais públicos e privados (Toscano, 2003).

Por serem escassos os recursos, não é possível atender aos desejos de todos os grupos sociais. Contudo, conforme afirma Toscano (2003): “... considerar-se-á eficaz o processo de escolha sempre que existir uma cesta mínima de bens e serviços à qual, presumivelmente, todos possam ter acesso, antes que produtos menos essenciais sejam produzidos".

Conforme ensina a teoria microeconômica tradicional, a intervenção estatal nas atividades econômicas justifica-se pela existência de falhas que fazem com que os mercados se afastem dos paradigmas de eficiência econômica.

Esse conceito pode ser entendido sob três óticas distintas: eficiência produtiva, 
alocativa e dinâmica (BIDERman; Arvate, 2004).

Para Fagundes (1998), eficiência produtiva significa "operar sobre uma dada função de produção (e não abaixo dela) e, ao fazê-lo, minimizar custos de produção".

Já o conceito de eficiência alocativa diz respeito à escolha mais eficiente de combinação dos insumos para a produção dos bens e serviços pela economia. Segundo Losekann (2003), a eficiência alocativa é avaliada pela proximidade entre preços $(\mathrm{P})$ praticados no mercado e custo marginal $(\mathrm{Cmg})$. A relação $(\mathrm{P}-\mathrm{Cmg}) / \mathrm{P}$ - o Índice de Lerner - seria uma medida da eficiência alocativa, ou de seu oposto, do poder de mercado para avaliar a eficiência no curto prazo das experiências de reforma do setor elétrico.

Gonçalves (2004) esclarece que a eficiência dinâmica refere-se à “... capacidade de sustentar elevadas taxas de crescimento no longo prazo. Esse conceito combina, assim, a importante questão estática (de curto prazo) relativa à alocação de recursos, com o dinamismo de longo prazo - rápida acumulação (altas taxas de investimento), crescimento do emprego, aumento contínuo de produtividade e absorção do progresso técnico".

Historicamente, o modelo de organização industrial adotado pelo setor elétrico fundamenta-se na teoria do monopólio natural, que se caracteriza pela presença de elevados custos fixos e economias de escala e escopo, limitando o número de firmas capazes de atingir uma escala mínima eficiente de produção.

Conforme resume Grijó (2001):

"No caso das utilities, o monopólio natural apresenta, ainda, duas outras características essenciais: 1) estabelecese em mercados cujos produtos são de demanda generalizada e preçoinelástico dada a sua essencialidade e 2) compõe-se de ativos específicos e irrecuperáveis (sunk costs) face às especificidades locacionais".

Contudo, conforme ressaltam Pinto Jr. e Silveira (1999), “... a questão da essencialidade do produto, confere, por um lado, um atributo de interesse público ao serviço prestado. Por outro, essas

"No setor elétrico

brasileiro, coexistem

a atuação direta do

Estado pelas empresas

de geração

controladas pelo

Grupo Eletrobrás, cujo

acionista majoritário é

o governo federal, $e$

a ação reguladora da

Aneel, que estabelece

regras para a atuação

das empresas de

geração, transmissão $e$

distribuição.”

características contribuem para fortalecer a justificativa econômica para a organização dessas indústrias em regime de monopólio", o que é indesejável do ponto de vista sócio-econômico.

Assim, o monopólio privado, ao objetivar a maximização de lucros, procura produzir e vender uma quantidade de bens que satisfaça à condição de que a receita resultante da venda de uma quantidade 
adicional do produto (a receita marginal) seja igual ao custo marginal da produção. Existe, no entanto, espaço para o monopólio avançar alocando recursos para produzir mais e vender a um menor preço um bem ou serviço. A tendência do monopólio privado é de não ocupar esse espaço, porque fica além da fronteira de obtenção de lucro máximo como empresa individual.

Dessa forma, o monopólio opera com menor eficiência alocativa em relação à concorrência perfeita. Essa ineficiência alocativa decorre justamente da perda da renda social. Ao ofertar uma quantidade menor, o monopólio produz com um custo unitário maior, provocando perda de renda da sociedade. Dessa forma, observa-se uma má alocação dos recursos da economia, uma vez que com os mesmos recursos disponíveis um produto menor é gerado. (Possas; Fagundes; Pondé, 1998).

Portanto, o custo social do monopólio (ou peso morto) refere-se à parcela da renda total (renda dos consumidores mais renda dos vendedores) que se perde quando ocorre redução da oferta e aumento do preço no monopólio.

É nesse contexto que se insere a discussão acerca da importância da eficiência alocativa e dinâmica e da atuação do Estado no setor elétrico brasileiro, seja como produtor direto ou regulador das atividades empresariais

Isso porque, na presença de condições de monopólio, resta ao poder público três alternativas: deixar o monopolista privado atuar livremente, comprometendo o bemestar econômico e social; ofertar diretamente o produto ou serviço; ou regular o mercado (SANTACRUZ, 2002).

A produção direta de bens e serviços pelo governo seria justificada quando o mecanismo de mercado se revelasse incapaz de propiciar uma alocação eficiente de recursos para a produção de bens públicos e bens meritórios, cujos conceitos são originários da teoria das finanças públicas.

Os primeiros se distinguem pela indivisibilidade de consumo, característica que torna impossível a determinação de seus preços pelo mercado e dificulta a decisão de investir em sua produção por parte do empresário privado.

Em contrapartida, se a oferta dos bens meritórios, que se caracterizam por gerar externalidades positivas (STIGLITZ, 2000), não é julgada satisfatória pela coletividade, sua expansão deveria se dar ou pela substituição da produção privada pela pública ou pela interferência nas decisões de produção privada por meio de incentivos e subsídios à expansão da produção desses bens.

Silva (1980), ao iniciar a discussão sobre o espaço a ser ocupado pela empresa pública em uma economia de mercado, lembra que "a hipótese de que a produção privada é mais eficiente que a produção pública baseia-se na descentralização de decisões e no anonimato das informações, que supostamente caracterizam um sistema baseado na iniciativa privada".

Contudo, conforme argumenta o autor, em uma economia em que a distribuição de poder é desigual e as decisões centralizadas, a correção dos desequilíbrios pode requerer uma intervenção mais direta na produção.

Já o conceito de regulação pública, originário da teoria da regulação, parte do princípio de uma atuação reduzida do Estado, cabendo-lhe garantir os incentivos para que a iniciativa privada oferte os produtos e serviços, mediante algumas restrições na autonomia empresarial. Assim, a regulação seria justificável em mercados concentrados com elevadas barreiras à entrada e demanda inelástica, uma vez que essas condições desequilibram as relações de mercado entre ofertantes e demandantes, 
retirando a eficiência do mercado (SANTACRUZ, 2002).

Em resumo, o marco teórico, sobre o qual repousa a justificativa da existência da empresa pública, aponta no sentido da cobrança de um preço que leve em conta uma estimativa dos custos futuros da expansão (custo marginal). Obedecendo a esse critério, a sociedade como um todo seria beneficiada com os consumidores ajustando adequadamente o consumo do bem e os produtores ajustando, por seu turno, seus planos de investimento a esse consumo. Como resultado, a tarefa que cabe ao governo, de promoção de ajustamentos na alocação de recursos na economia, teria sido eficientemente cumprida.

Entretanto, a tarefa de definição de um modelo de intervenção do Estado não é trivial.

No setor elétrico brasileiro, coexistem os dois modelos aqui citados, ou seja, o de atuação direta do Estado por meio das empresas de geração controladas pelo Grupo Eletrobrás ${ }^{1}$, cujo acionista majoritário é o governo federal, responsáveis pela produção de cerca de $60 \%$ da energia elétrica consumida no País; e o da ação reguladora da Agência Nacional de Energia Elétrica (Aneel), que estabelece regras para a atuação das empresas nos três segmentos (geração, transmissão e distribuição), buscando propiciar condições favoráveis para que o mercado de energia elétrica se desenvolva com equilíbrio entre ofertantes e consumidores.

\section{Análise dos indicadores de eficiência alocativa no setor elétrico brasileiro no período 1995-2005}

Primeiramente, cabe destacar a dificuldade de mensurar eficiência alocativa no setor elétrico brasileiro por não estarem disponíveis os custos das concessionárias. Por essa razão, o presente trabalho utilizará como proxy de um indicador de eficiência alocativa a evolução da tarifa média de energia frente aos diferentes índices de preços da economia e seus possíveis reflexos sobre o consumo de energia e sobre os resultados financeiros das empresas.

Conforme mostra a Tabela 1, no período 1995-2005, o índice de evolução da tarifa média superou a evolução de diversos índices relevantes de preços na economia.

Considerando a evolução do Deflator Implícito do Produto (melhor indicador do comportamento dos preços em geral na economia por ser construído a partir da comparação do valor global da produção de bens e serviços em diferentes anos), o ganho real na tarifa, ao final do período 1995-2005, acumulava 65,3\%; com relação ao IGP-M, esse ganho era de $47 \%$, e com relação ao IPCA, o ganho real na tarifa, ao final do período, acumulava cerca de $95 \%$.

A legislação atual sobre o setor elétrico ampara indústria, comércio e prestadoras de serviços, entre outras atividades consumidoras de energia elétrica para migrarem ao mercado livre, se assim o desejarem, desde que tenham demanda mínima contratada de 3 mil kW, sejam atendidos em tensão igual ou superior a $69 \mathrm{kV}$ ou tenham solicitado ligação em qualquer tensão a partir de julho de 1995.

Isso contribui para que, como se observa na Tabela 2, o consumidor residencial, quando comparado ao industrial e ao comercial, tenha sido o mais penalizado pela política de repasses dos encargos tarifários, fato que se percebe claramente no período 1995-2004. Em 2005, o governo iniciou um processo de correção das distorções, elevando substancialmente as tarifas industriais. 
Tabela 1: Índices de evolução de preços na economia (base 1995=100)

\begin{tabular}{c|c|c|c|c}
\hline Ano & Deflator Implícito do PIB & IGP-M (FGV) & IPCA(IBGE) & Tarifa média \\
\hline 1995 & 100,0 & 100,0 & 100,0 & 100,0 \\
\hline 1996 & 117,4 & 109,2 & 109,6 & 125,0 \\
\hline 1997 & 127,1 & 117,6 & 115,3 & 137,9 \\
\hline 1998 & 133,3 & 119,8 & 117,1 & 145,3 \\
\hline 1999 & 140,9 & 143,8 & 127,6 & 160,9 \\
\hline 2000 & 152,6 & 158,1 & 135,2 & 182,1 \\
\hline 2001 & 164,0 & 174,5 & 145,6 & 206,2 \\
\hline 2002 & 180,7 & 218,7 & 163,8 & 240,1 \\
\hline 2003 & 207,7 & 237,7 & 179,1 & 280,6 \\
\hline 2004 & 224,5 & 267,2 & 192,7 & 331,2 \\
\hline 2005 & 240,4 & 270,4 & 203,6 & 397,3 \\
\hline
\end{tabular}

Fontes: IBGE, FGV e Aneel. Elaboração própria.

Tabela 2: Índice de evolução da tarifa média real (base 1995=100)

\begin{tabular}{l|c|c|c|c}
\hline Ano & Residencial & Industrial & Comercial & Total \\
\hline 1995 & 100,0 & 100,0 & 100,0 & 100,0 \\
\hline 1996 & 127,6 & 105,6 & 106,4 & 114,1 \\
\hline 1997 & 136,3 & 108,7 & 109,6 & 119,6 \\
\hline 1998 & 141,3 & 110,7 & 111,5 & 124,1 \\
\hline 1999 & 142,8 & 113,5 & 111,6 & 126,1 \\
\hline 2000 & 154,1 & 120,5 & 118,4 & 134,7 \\
\hline 2001 & 161,9 & 129,5 & 125,6 & 141,7 \\
\hline 2002 & 167,9 & 134,1 & 132,6 & 146,6 \\
\hline 2003 & 175,2 & 143,3 & 137,5 & 156,7 \\
\hline 2004 & 184,1 & 163,3 & 144,9 & 171,9 \\
\hline 2005 & 198,2 & 220,3 & 159,6 & 206,2 \\
\hline
\end{tabular}

Fonte: IBGE, FGV e Aneel. Elaboração própria. Deflator: IPCA - IBGE

Os consumidores que migram para o mercado livre ficam desobrigados de participar do rateio de compra de energia da Itaipu Binacional, que embute um risco cambial. O mesmo aplica-se ao rateio da Recomposição Tarifária Extraordinária (RTE), uma sobretarifa criada para recompor as perdas de faturamento e as despesas oriundas da energia comercializada no Mercado Atacadista de Energia durante a vigência do Programa de Racionamento de 2001. Esses dois ônus tendiam a recair sobre os consumidores cativos, como o residencial. 
Carlos Rodolfo Schneider (2005) avalia que os próprios subsídios aplicados sobre o custo da energia paga por determinados consumidores, como cooperativas de eletrificação rural e empresas públicas prestadoras de serviços de água, esgoto e saneamento, considerados justos pelo seu caráter social, agora são bancados apenas pelos consumidores cativos. Para o autor, a legislação de 1995, que norteia o setor elétrico em relação ao assunto, amparava essa distorção ao afirmar que "as tarifas das concessionárias envolvidas na opção do consumidor poderão ser revisadas para mais ou para menos quando a perda ou o ganho de mercado alterar o equilíbrio econômico-financeiro do contrato", o que legitima, na prática, a posição atual de novos reajustes levando em conta apenas o mercado cativo.

Esta evolução diferenciada das tarifas já possui impactos visíveis sobre a dinâmica do mercado, como mostra a Tabela 3. A forte redução no índice de elasticidade-renda ${ }^{2}$ do consumo residencial, a partir de 1999, pode ser atribuída, além do racionamento de 2001, ao efeito-preço decorrente dessa evolução, conforme observado na Tabela 4.

A evolução das tarifas ao consumidor final tem, a despeito desses efeitos sobre o mercado, contribuído para a acentuação dos ganhos auferidos pelas empresas distribuidoras quando comparados, por exemplo, aos ganhos do Grupo Eletrobrás.

Nas Tabelas 5 e 6 , observa-se a evolução real do $\mathrm{EBITDA}^{3}$ - que representa a geração operacional de caixa - das empresas do Grupo Eletrobrás constituído por geradoras estatais; das distribuidoras associadas à Abradee ${ }^{4}$, que, em sua maioria, são empresas privadas; e as demais empresas ${ }^{5}$, compostas por geradoras e transmissoras privadas.

Tabela 3: Índices de evolução do consumo de energia elétrica e do PIB (base 1995=100)

\begin{tabular}{l|c|c|c|c|l}
\hline Ano & Residencial & Industrial & Comercial & Total & PIB \\
\hline 1994 & 100,0 & 100,0 & 100,0 & 100,0 & 100,0 \\
\hline 1995 & 113,4 & 103,3 & 111,7 & 107,2 & 104,2 \\
\hline 1996 & 122,3 & 105,0 & 119,0 & 111,8 & 107,0 \\
\hline 1997 & 132,1 & 110,3 & 132,2 & 119,4 & 110,5 \\
\hline 1998 & 141,5 & 110,1 & 143,8 & 124,0 & 110,6 \\
\hline 1999 & 145,0 & 109,6 & 150,8 & 126,2 & 111,5 \\
\hline 2000 & 149,1 & 115,7 & 164,8 & 132,6 & 116,4 \\
\hline 2001 & 131,3 & 108,0 & 153,8 & 122,2 & 117,9 \\
\hline 2002 & 129,7 & 113,0 & 156,5 & 125,3 & 120,2 \\
\hline 2003 & 135,8 & 120,0 & 164,5 & 132,4 & 120,8 \\
\hline 2004 & 139,9 & 128,7 & 171,9 & 138,3 & 126,8 \\
\hline 2005 & 147,5 & 131,8 & 184,3 & 144,7 & 129,7 \\
\hline
\end{tabular}

Fontes: Eletrobrás e IBGE. Elaboração própria. 
Tabela 4: Evolução do índice de elasticidade-renda do consumo de energia elétrica - Ano base: 1994

\begin{tabular}{l|c|c|c|c}
\hline Ano & Residencial & Industrial & Comercial & Total \\
\hline 1995 & 1,09 & 0,99 & 1,07 & 1,03 \\
\hline 1996 & 1,14 & 0,98 & 1,11 & 1,04 \\
\hline 1997 & 1,20 & 1,00 & 1,20 & 1,08 \\
\hline 1998 & 1,28 & 1,00 & 1,30 & 1,12 \\
\hline 1999 & 1,30 & 0,98 & 1,35 & 1,13 \\
\hline 2000 & 1,28 & 0,99 & 1,42 & 1,14 \\
\hline 2001 & 1,11 & 0,92 & 1,30 & 1,04 \\
\hline 2002 & 1,08 & 0,94 & 1,30 & 1,04 \\
\hline 2003 & 1,12 & 0,99 & 1,36 & 1,10 \\
\hline 2004 & 1,10 & 1,02 & 1,36 & 1,09 \\
\hline 2005 & 1,14 & 1,02 & 1,42 & 1,12 \\
\hline
\end{tabular}

Fontes: IBGE. Elaboração própria.

Tabela 5: Evolução do EBTIDA - (R\$ milhões de 2005)

\begin{tabular}{c|c|c|c|c}
\hline Ano & Grupo Eletrobrás & Distribuidoras Abradee & Demais empresas & Total \\
\hline 1995 & 2709,5 & 5662,1 & 1702,4 & 10074,0 \\
\hline 1996 & 3381,7 & 5948,8 & 2438,4 & 11768,9 \\
\hline 1997 & 3983,4 & 5977,1 & 2050,9 & 12011,4 \\
\hline 1998 & 4110,7 & 9507,8 & 3340,5 & 16959,0 \\
\hline 1999 & 4246,8 & 9613,0 & 3000,1 & 16859,9 \\
\hline 2000 & 4797,7 & 11146,4 & 4019,0 & 19963,1 \\
\hline 2001 & 6494,3 & 14277,1 & 4730,7 & 25502,1 \\
\hline 2002 & 4696,9 & 8538,4 & 4186,5 & 17421,8 \\
\hline 2003 & 6052,1 & 10281,0 & 4705,8 & 21038,9 \\
\hline 2004 & 4850,2 & 12262,6 & 5415,3 & 22528,1 \\
\hline 2005 & 4555,6 & 13842,3 & 4364,9 & 22762,8 \\
\hline
\end{tabular}

Fonte: Demonstrações econômico-financeiras das empresas.

As distribuidoras mais que dobram o valor real do EBTIDA no período 1995-2005. O Grupo Eletrobrás, que também já havia mais que dobrado o valor do EBITDA nos anos de 2001 e 2003, perdeu participação no total do setor em 2004 e 2005. O rápido avanço da parcela referente às demais empresas, no período 1995-2005, deve-se principalmente à performance da Tractebel (ex-Gerasul), que só inicia a operação em 1998. 
Tabela 6: EBTIDA - Índice de evolução real (base 1995=100)

\begin{tabular}{l|c|c|c|c}
\hline Ano & Grupo Eletrobrás & Distribuidoras Abradee & Demais empresas & Total \\
\hline 1995 & 100,0 & 100,0 & 100,0 & 100,0 \\
\hline 1996 & 124,8 & 105,1 & 143,2 & 116,8 \\
\hline 1997 & 147,0 & 105,6 & 120,5 & 119,2 \\
\hline 1998 & 151,7 & 167,9 & 196,2 & 168,3 \\
\hline 1999 & 156,7 & 169,8 & 176,2 & 167,4 \\
\hline 2000 & 177,1 & 196,9 & 236,1 & 198,2 \\
\hline 2001 & 239,7 & 252,2 & 277,9 & 253,1 \\
\hline 2002 & 173,3 & 150,8 & 245,9 & 172,9 \\
\hline 2003 & 223,4 & 181,6 & 276,4 & 208,8 \\
\hline 2004 & 179,0 & 216,6 & 318,1 & 223,6 \\
\hline 2005 & 168,1 & 244,5 & 256,4 & 226,0 \\
\hline
\end{tabular}

Fonte: Demonstrações econômico-financeiras das empresas. Elaboração própria. Deflator: Deflator Implícito do Produto.

A evolução do EBITDA das distribuidoras e demais empresas mostra que esses segmentos já aparecem como um espaço privilegiado de acumulação de recursos no setor a partir de 1998 (em parte, devido à saída da parte de geração da Eletrosul), mantendo-se nesse "status" até 2002, quando o racionamento afetou o segmento de distribuição de uma forma mais que proporcional ao que ocorreu com os demais. A recuperação, no entanto, iniciase já em 2003 e prossegue de forma sustentada em 2004 e 2005.

Análise dos indicadores de eficiência dinâmica do setor elétrico brasileiro

Esta seção procura avaliar a eficiência dinâmica do setor elétrico brasileiro, ou seja, sua capacidade de promover crescimento sustentado de longo prazo.

Para tanto, primeiramente, temos que examinar as condições de curto prazo relativas à alocação de recursos que servem de base para esse crescimento, o que passa necessariamente pela análise da evolução dos investimentos das empresas públicas e privadas nos últimos anos.

Nesta seção, a evolução dos indicadores de avaliação da eficiência dinâmica partirá de duas concepções metodológicas já desenvolvidas e aplicadas em um horizonte mais amplo de formação bruta de capital e utilizadas, para o caso do setor de energia elétrica, por Alves e Almeida (2003).

A primeira concepção metodológica consiste em um modelo macroeconômico formulado por Melo e Rodrigues Jr. (1998). A segunda, em colaborações teóricas da Escola de Cambridge, formuladas a partir das reflexões formuladas por J. Steindl e resgatadas pela professora Maria da Conceição Tavares em seu livro Acumulação de capital e industrialização no Brasil (1998). A consideração desse modelo teria por objetivo incluir uma observação mais atenta a respeito dos fatores relacionados aos 
determinantes endógenos da expansão sustentada (eficiência dinâmica) do setor de energia elétrica.

O modelo desenvolvido por Melo e Rodrigues Jr. (1998) discute os fatores relevantes que determinam o investimento privado no Brasil, sugerindo que as políticas públicas de estímulo a esse tipo de investimento no País passam necessariamente pela garantia de crescimento econômico, pela manutenção das taxas de juros em níveis moderados e pela estabilidade nos preços domésticos. Tais elementos são descritos como peças fundamentais na redução da incerteza e no fortalecimento da credibilidade por parte dos agentes privados.

A equação estimada por Melo e Rodrigues Jr. (1998) é apresentada a seguir:

\section{$\mathrm{IPt}=-2,0282+1,1576 \mathrm{Yt}-0,1035 \mathrm{IGt}-$ 0,0040 Rt - 0,0715 Pt}

Onde:

IP $=$ Investimento Bruto do Setor Público, excluindo as companhias estatais

$\mathrm{Y}=$ Produto Interno Bruto

$\mathrm{IG}=$ Investimento Bruto do Setor Privado (administrações públicas companhias estatais);

$\mathrm{R}=$ Taxa Real de Juros

$\mathrm{P}=$ Taxa Anual de Inflação

$\mathrm{t}=$ Ano

De uma forma geral, os indicadores derivados do modelo referem-se a indicadores de conjuntura, cujo acompanhamento permitiria acionar políticas anti-cíclicas quando necessário. $\mathrm{O}$ acionamento dessas políticas é evidentemente tarefa de outros órgãos governamentais e não de agentes reguladores setoriais, mas seu acompanhamento por parte desses agentes permite o conhecimento das possibilidades de alcance das metas de eficiência, levando em conta os obstáculos impostos por fatores exógenos e atuações no âmbito setorial visando a compensar esses mesmos obstáculos.

No modelo de determinação dos investimentos no longo prazo atribuído a Steindl (1983), são introduzidos explicitamente e não apenas como explicação do ciclo, o grau de endividamento e a utilização da capacidade instalada. A interação entre os determinantes do investimento e a própria taxa efetiva de acumulação conduz, no modelo mencionado, ao processo de crescimento de longo prazo, cujas equações dinâmicas podem ser descritas da seguinte forma:

$$
\begin{aligned}
& (\mathrm{dz} / \mathrm{dt}) / \mathrm{Z}=(\mathrm{ds} / \mathrm{dt}) / \mathrm{S}+(\mathrm{dk} / \mathrm{dt}) / \mathrm{K}- \\
& (\mathrm{du} / \mathrm{dt}) / \mathrm{U}=(\mathrm{dg} / \mathrm{dt}) / \mathrm{G}+(\mathrm{dc} / \mathrm{dt}) / \mathrm{C} \\
& \mathrm{It}+\theta=\mathrm{aCt}+\mathrm{U}(\mathrm{ut})-\mathrm{G}(\mathrm{gt})+\mathrm{P}(\mathrm{pt}) \\
& (\mathrm{dz} / \mathrm{dt}) / \mathrm{Z}=\text { Taxa de Crescimento do } \\
& \text { Capital Total (Acumulação) } \\
& (\mathrm{ds} / \mathrm{dt}) / \mathrm{S}=\text { Taxa de Crescimento das } \\
& \text { Vendas ou da Produção } \\
& \text { Efetiva } \\
& (\mathrm{dk} / \mathrm{dt}) / \mathrm{K}=\text { Taxa de Variação da } \\
& \text { Intensidade de Capital } \\
& (\mathrm{du} / \mathrm{dt}) / \mathrm{U}=\text { Taxa de Crescimento do } \\
& \text { Endividamento das Empresas } \\
& \text { (dg/dt)/G= Taxa de Crescimento do } \\
& \text { Grau de Utilização } \\
& (\mathrm{dc} / \mathrm{dt}) / \mathrm{C}=\text { Taxa de Crescimento dos } \\
& \text { Lucros Retidos ou do } \\
& \text { Capital Próprio } \\
& \mathrm{P}(\mathrm{pt})=\text { Taxa de Lucro }
\end{aligned}
$$

Aplicando os modelos de determinação dos investimentos à realidade do setor elétrico brasileiro, Alves e Almeida (2003) concluíram que, durante o período 1995-2001, o comportamento da conjuntura favoreceu, sobremaneira, a sustentabilidade das inversões 
privadas no setor elétrico brasileiro ocorrida predominantemente até 1998.

Outro fator importante para a concretização dos fluxos de inversões privadas no setor teria sido o fim do efeito crowding out ${ }^{6}$ verificado predominantemente durante o período 1970/95. No período imediatamente posterior, a redução da participação do setor público na formação bruta de capital fixo do País cedeu espaço para um avanço mais que proporcional do setor privado na formação bruta de capital fixo.

A relevância do efeito acelerador do produto sobre o investimento privado teria sido o fator isoladamente mais importante, na medida em que a expectativa consolidada de um crescimento sustentado orientou grande parte das estratégias de investimento dos novos players no setor elétrico nacional a partir de sua abertura em meados da década de 90. Observando uma queda relativa nas inversões privadas após 1998, Alves e Almeida (2003) afirmam que a queda nas taxas reais de juros após aquele ano teria impedido uma redução mais expressiva do investimento privado no setor elétrico nos anos pós 1998.

Os autores observaram que, entre 1995 e 2001, a relação investimentos/ ativos totais cresceu 2,2\%, em média, ao ano, entre as empresas de controle estatal. Entre as concessionárias de capital privado, o indicador caiu em média 4,1\% ao ano, demonstrando que os fatores relativos à conjuntura macroeconômica não teriam sido suficientes para explicar o que teria resultado na retração nos fluxos de investimentos no setor.

Passando à observação do comportamento do setor elétrico brasileiro entre 1995 e 2001 à luz do sistema de equações descritas pelo modelo de Steindl (1983), Alves e Almeida (2003) constataram que o capital próprio das empresas do setor elétrico brasileiro caiu progressivamente a partir de 1995, mostrando que as empresas do setor não reverteram renda suficiente para atenuar a corrosão inflacionária sobre o valor dos investimentos de seus acionistas.

Isso não significa, necessariamente, que eles não tenham sido remunerados, mas certamente demonstra uma transferência líquida de recursos para o ambiente extra-setorial, ou seja, um movimento

“As diferentes
estratégias de
alocação de
recursos das
empresas privadas
devem ser
acompanbadas pelo
Estado, buscando a
necessária
coordenação entre
elas, afim de
promover a
expansão
sustentada dos
investimentos dos
diversos segmentos."

evidente de desacumulação. A evolução do capital próprio das companhias do setor elétrico estaria sinalizando, segundo os autores, uma estratégia predatória dos sócios controladores em relação aos negócios nos quais estavam sendo aplicados seus recursos - fator deveras inibidor de novas inversões.

O grau de endividamento das empresas de energia elétrica estaria desempenhando um papel fundamental na potencialização 
desse fenômeno. As dívidas do setor teriam crescido, em média, $13,5 \%$ ao ano em termos reais no período 1995-2001, por força do endividamento das empresas privadas, uma vez que as empresas públicas mantiveram o mesmo montante de obrigações financeiras no período.

Seria possível compreender as disparidades na evolução das dívidas no segmento estatal e não estatal em função das privatizações ocorridas e das transferências de dívidas associadas a ativos antes sob controle de empresas públicas, se não fosse pelo fato de que a velocidade de crescimento de empréstimos e financiamentos foi maior do que o ritmo de transferência de ativos. Entre as empresas estatais, a queda no valor real agregado dos ativos totais de $8,5 \%$ ao ano ocorreu simultaneamente à manutenção do montante real de valores devidos, fazendo crescer o grau de endividamento dessas companhias de $16,7 \%$ para 31\% entre 1995 e 2001.

Entre as empresas privadas, o crescimento médio no valor real de ativos sob gestão não estatal foi de $62,5 \%$ ao ano. Em contrapartida, as dívidas expandiram-se em média $142,3 \%$ ao ano durante o período, elevando o grau de endividamento de 7,5\% para 50,7\%. Esse aspecto foi decisivo para, apesar dos fatores positivos demonstrados no modelo de Melo e Rodrigues Jr. (1998), impedir que os investimentos nas empresas privadas do setor elétrico continuassem a crescer. Foi, além disso, determinante para que a relação investimentos/ativos de capital caísse tão intensamente no período 19982001, ao contrário do que ocorreu nas empresas estatais, apesar de suas peculiaridades operacionais.

Com base na constatação de que o crescimento do capital total acumulado (ativos totais) foi negativo entre 1995 e 2001 - equivalente a uma taxa média anual de $1,5 \%$ - e de que as dívidas do setor elevaram-se às taxas mencionadas, Alves e Almeida (2003) concluíram que, durante aquele período, as empresas foram forçadas a manter o ritmo acelerado de transferência de rendas para financiadores e investidores em capital.

Partindo do conceito de taxa de lucro como a relação fluxo operacional de caixa ${ }^{7}$ e investimentos acumulados ${ }^{8}$, Alves e Almeida (2003) revelaram que, em termos reais, essa taxa, no setor elétrico brasileiro, passou de 2,2\%, em 1995, para 9,4\% em 2001. O crescimento da taxa de lucro foi constante e positivo durante todo o período, mostrando que, apesar de todos os problemas estruturais e conjunturais por que passou o setor e a economia em geral, a viabilidade de retornos para o capital foi permanentemente ampliada.

$\mathrm{Na}$ avaliação final dos autores, entretanto, o elemento central de sustentação dos investimentos no setor elétrico brasileiro, desde a sua abertura à gestão privada, teria sido o elevado nível de endividamento assumido, sobretudo, pelas concessionárias não estatais. A redução progressiva da escala de acumulação total teria sido fundada, única e exclusivamente, no crescimento acelerado do grau de endividamento dessas empresas, comprometendo decisivamente todos os demais fatores que poderiam estimular o investimento no setor, a despeito das instabilidades do cenário macroeconômico nacional.

Mercado em expansão, retornos reais elevados e geração de renda sobre o investimento crescente seriam peças-chave para a sustentação dos investimentos no setor. Contudo, foram utilizadas para potencializar os efeitos inibidores a novas inversões. Ao invés de alimentar o processo de acumulação, oferecendo robustez financeira ao setor e autonomia de recursos próprios para a sua 
expansão, esses fatores fizeram acelerar a transferência de recursos intra-setoriais para o setor financeiro e para carteira de aplicações extra-setoriais, por meio da realocação das rendas recebidas pelos sócios controladores de empresas do setor.
As estratégias de destinação dos resultados de algumas empresas do setor elétrico estão por trás da queda (em 2003) e relativa estagnação (em 2004) no nível de investimentos para a ampliação da capacidade produtiva, conforme se observa nas

Tabela 7: Investimentos - R\$ milhões de 2005

\begin{tabular}{l|c|c|c|c}
\hline Ano & Grupo Eletrobrás & Distribuidoras Abradee & Demais empresas & Total \\
\hline 1995 & $2.661,7$ & $5.694,2$ & $2.094,0$ & $10.449,9$ \\
\hline 1996 & $3.170,2$ & $5.698,6$ & $1.930,7$ & $10.799,5$ \\
\hline 1997 & $4.016,4$ & $6.450,2$ & $2.864,3$ & $13.330,9$ \\
\hline 1998 & $5.166,9$ & $8.112,3$ & $2.998,2$ & $16.277,5$ \\
\hline 1999 & $4.916,6$ & $6.950,2$ & $2.692,3$ & $14.559,2$ \\
\hline 2000 & $3.515,0$ & $6.151,9$ & $3.568,1$ & $13.235,0$ \\
\hline 2001 & $3.613,2$ & $6.375,2$ & $2.783,3$ & $12.771,7$ \\
\hline 2002 & $4.477,1$ & $5.543,7$ & $2.436,7$ & $12.457,5$ \\
\hline 2003 & $3.302,0$ & $4.504,0$ & $1.570,6$ & $9.376,6$ \\
\hline 2004 & $3.069,1$ & $5.329,0$ & $1.047,8$ & $9.445,9$ \\
\hline 2005 & $2.998,5$ & $7.221,4$ & 937,5 & $11.157,5$ \\
\hline
\end{tabular}

Fonte: Demonstrações econômico-financeiras das empresas.

Tabela 8: Índice de evolução real dos investimentos (base 1995=100)

\begin{tabular}{l|c|c|c|c}
\hline Ano & Grupo Eletrobrás & Distribuidoras Abradee & Demais & Total \\
\hline 1995 & 100,0 & 100,0 & 100,0 & 100,0 \\
\hline 1996 & 119,1 & 100,1 & 92,2 & 103,3 \\
\hline 1997 & 150,9 & 113,3 & 136,8 & 127,6 \\
\hline 1998 & 194,1 & 142,5 & 143,2 & 155,8 \\
\hline 1999 & 184,7 & 122,1 & 128,6 & 139,3 \\
\hline 2000 & 131,0 & 108,0 & 170,4 & 126,4 \\
\hline 2001 & 135,7 & 112,0 & 132,9 & 122,2 \\
\hline 2002 & 168,2 & 97,4 & 116,4 & 119,2 \\
\hline 2003 & 124,1 & 79,1 & 75,0 & 89,7 \\
\hline 2004 & 115,6 & 89,5 & 50,2 & 88,3 \\
\hline 2005 & 112,7 & 126,8 & 44,8 & 106,8 \\
\hline
\end{tabular}

Fonte: Demonstrações econômico-financeiras das empresas. Elaboração própria. 
Tabelas 7 e 8 . A recuperação da taxa de investimentos das distribuidoras só começa a favorecer o aumento do valor real dos investimentos do setor elétrico em 2005.

$\mathrm{Na}$ Tabela 9, observa-se que a geração de caixa operacional (EBITDA) das distribuidoras e demais empresas tem sido predominantemente reservada, nos últimos anos, para outros usos que não à aquisição distribuidoras em 2004 foi acompanhada de uma redução desse percentual.

Para a evolução do perfil de alocação de recursos, apresentada na Tabela 9, contribui o fato de que algumas empresas do setor elétrico têm ultrapassado o limite mínimo de $25 \%$ do lucro líquido para distribuir em dividendos ou juros sobre o capital próprio estabelecido pela Lei das

Tabela 9: Evolução dos investimentos como percentagem do EBITDA

\begin{tabular}{c|c|c|c|c}
\hline Ano & Grupo Eletrobrás & Distribuidoras Abradee & Demais empresas & Total \\
\hline 1995 & $98,2 \%$ & $100,6 \%$ & $123,0 \%$ & $103,7 \%$ \\
\hline 1996 & $93,8 \%$ & $95,8 \%$ & $79,2 \%$ & $91,8 \%$ \\
\hline 1997 & $100,8 \%$ & $107,9 \%$ & $139,7 \%$ & $111,0 \%$ \\
\hline 1998 & $125,7 \%$ & $85,3 \%$ & $89,8 \%$ & $96,0 \%$ \\
\hline 1999 & $115,8 \%$ & $72,3 \%$ & $89,7 \%$ & $86,4 \%$ \\
\hline 2000 & $73,3 \%$ & $55,2 \%$ & $88,8 \%$ & $66,3 \%$ \\
\hline 2001 & $55,6 \%$ & $44,7 \%$ & $58,8 \%$ & $50,1 \%$ \\
\hline 2002 & $95,3 \%$ & $64,9 \%$ & $58,2 \%$ & $71,5 \%$ \\
\hline 2003 & $54,6 \%$ & $43,8 \%$ & $33,4 \%$ & $44,6 \%$ \\
\hline 2004 & $63,3 \%$ & $43,5 \%$ & $19,4 \%$ & $42,0 \%$ \\
\hline 2005 & $65,8 \%$ & $52,2 \%$ & $21,5 \%$ & $49,0 \%$ \\
\hline
\end{tabular}

Fonte: Demonstrações econômico-financeiras das empresas. Elaboração própria.

de imobilizado (ou seja, investimentos visando à expansão da capacidade produtiva).

Entre esses usos, destaca-se a ampliação da distribuição de dividendos e juros sobre capital. Uma justificativa para essa decisão das empresas de privilegiar seus acionistas é o fato de terem passado algum tempo registrando prejuízo e precisarem remunerar seus investidores agora que os lucros voltaram. A redução dos investimentos como percentagem do EBITDA, embora comum a todos os segmentos, é menos acentuada no caso do Grupo Eletrobrás. Observa-se, inclusive, que a ligeira elevação na taxa de investimentos das empresas
Sociedades Anônimas para as companhias abertas.

Segundo matéria de 05/07/2005 publicada no Canal Energia, o grupo CPFL Energia, por exemplo, com a entrada no Novo Mercado da Bolsa de Valores de São Paulo e no nível III da Bolsa de Nova Iorque, adotou como política a distribuição mínima de $50 \%$ do lucro líquido. No entanto, o montante distribuído em dividendos no ano de 2004 foi de 95\%. O grupo justifica essa destinação da quase totalidade do lucro líquido para dividendos alegando ter conseguido suprir as suas necessidades de investimento de outras formas. 
A Cemig também adotou como política de dividendos a distribuição de $50 \%$ do lucro líquido para os acionistas por semestre, podendo haver distribuição extraordinária. Em 2002, por exemplo, foram pagos $\mathrm{R} \$ 220$ milhões em dividendos, passando para $\mathrm{R} \$ 320$ milhões em 2003 e para R $\$ 692$ milhões em 2004, valor que corresponde a $80 \%$ do valor dos investimentos na atividade produtiva, que somou $\mathrm{R} \$ 875,1$ milhões.

A Tabela 10 evidencia as evoluções da relação investimento/ativo e da relação investimento/mercado de energia elétrica total. Nota-se que a relação investimento/ ativo das distribuidoras manteve-se acima dos demais até 1998, quando essa taxa começa a decrescer até 2004. O mesmo movimento declinante foi observado para as demais empresas de 2000 até 2005.

No que se refere à relação investimento/mercado, o Grupo Eletrobrás tem apresentado desempenho acima das distribuidoras e demais empresas durante o período analisado, com exceção dos anos 2000 e 2005.

Essas considerações sugerem que as diferentes estratégias de alocação de recursos das empresas privadas devem ser acompanhadas pelo Estado, buscando a necessária coordenação entre elas, a fim de promover a expansão sustentada dos investimentos dos diversos segmentos. Mostram também que a empresa pública é peça fundamental na preservação da eficiência alocativa e dinâmica no setor elétrico e na economia brasileira.

A análise dos dados leva-nos a crer que a capacidade de realização de investimentos de longo prazo das empresas privadas foi comprometida pelo alto nível de endividamento assumido. Além disso, a transferência de recursos intra-setoriais ocorrida em tempos recentes levanta dúvida sobre

Tabela 10: Evolução de indicadores selecionados

\begin{tabular}{c|c|c|c|c|c|c}
\hline & \multicolumn{3}{|c|}{$\%$ Investimento/ativo } & \multicolumn{2}{c}{$\begin{array}{l}\text { Índice da relação investimento/ } \\
\text { mercado (base 1995=100) }\end{array}$} \\
\hline Ano & $\begin{array}{l}\text { Grupo } \\
\text { Eletrobrás }\end{array}$ & $\begin{array}{l}\text { Distribuidoras } \\
\text { Abradee }\end{array}$ & $\begin{array}{l}\text { Demais } \\
\text { empresas }\end{array}$ & $\begin{array}{l}\text { Grupo } \\
\text { Eletrobrás }\end{array}$ & $\begin{array}{l}\text { Distribuidoras } \\
\text { Abradee }\end{array}$ & $\begin{array}{l}\text { Demais } \\
\text { empresas }\end{array}$ \\
\hline 1995 & $1,4 \%$ & $3,8 \%$ & $3,7 \%$ & 100,0 & 100,0 & 100,0 \\
\hline 1996 & $2,3 \%$ & $5,1 \%$ & $3,7 \%$ & 114,2 & 96,0 & 88,4 \\
\hline 1997 & $3,4 \%$ & $5,5 \%$ & $4,6 \%$ & 135,5 & 101,7 & 122,8 \\
\hline 1998 & $4,4 \%$ & $6,1 \%$ & $3,7 \%$ & 167,8 & 123,2 & 123,8 \\
\hline 1999 & $5,1 \%$ & $4,9 \%$ & $3,7 \%$ & 156,9 & 103,7 & 109,2 \\
\hline 2000 & $3,8 \%$ & $4,6 \%$ & $5,1 \%$ & 105,9 & 87,3 & 137,8 \\
\hline 2001 & $3,9 \%$ & $4,4 \%$ & $3,9 \%$ & 119,0 & 98,3 & 116,6 \\
\hline 2002 & $5,1 \%$ & $3,9 \%$ & $3,5 \%$ & 143,9 & 83,3 & 99,6 \\
\hline 2003 & $4,5 \%$ & $3,6 \%$ & $2,6 \%$ & 100,5 & 64,0 & 60,7 \\
\hline 2004 & $4,4 \%$ & $4,4 \%$ & $1,9 \%$ & 89,6 & 69,4 & 38,9 \\
\hline 2005 & $4,5 \%$ & $6,0 \%$ & $1,9 \%$ & 83,5 & 94,0 & 33,2 \\
\hline
\end{tabular}

Fonte: Demonstrações econômico-financeiras das empresas. Elaboração própria. 
a efetiva contribuição futura do setor privado para a consecução do crescimento sustentado, caso essa política se mantenha.

\section{Conclusão}

O arcabouço teórico da discussão acerca da eficiência econômica aponta para a hipótese de que um sistema baseado na iniciativa privada seria mais eficiente do que aquele com base na iniciativa pública, o que pressupõe a existência de um ambiente competitivo.

Contudo, esse conceito não se aplica ao setor elétrico. Percebe-se que as especificidades que envolvem a oferta desse serviço justificam, historicamente, a necessidade de intervenção estatal, seja sob a forma direta, com o Estado assumindo a oferta do serviço de energia elétrica e a realização de investimentos para assegurar sua provisão, seja pela regulação das atividades empresariais.

Alves e Almeida (2003) utilizaram os modelos de determinação dos investimentos desenvolvidos por Melo e Rodrigues Jr. (1998) e Steindl (1983) ao setor elétrico brasileiro e concluíram que a aceleração das inversões privadas no setor elétrico brasileiro durante o período 1995 2001, a despeito da desaceleração nas inversões em ativos imobilizados nas empresas estatais, foi promovida por meio do elevado nível de endividamento assumido pelas concessionárias não estatais.

Ademais, observou-se que os segmentos das empresas privadas, que vinham destacando-se como espaço privilegiado de acumulação de recursos, apresentou uma evolução declinante na sua taxa de investimentos, pelo menos até o ano de 2004.

Um importante aspecto que emerge dos resultados desse trabalho é que, independentemente das especificidades de cada grupo de empresas analisado (Grupo Eletrobrás, distribuidoras da Abradee e demais empresas), as diferentes estratégias de investimentos adotadas seguem lógicas distintas. O grupo das distribuidoras e demais empresas, nos quais se concentram grande parte das concessionárias privadas de energia elétrica, têm suas decisões pautadas pela lógica capitalista de obtenção de lucros e acumulação de riquezas. Esse fato fica evidenciado pelas decisões recentes de algumas empresas distribuidoras de privilegiar a remuneração dos acionistas em detrimento dos investimentos em aumento de capacidade produtiva.

O Grupo Eletrobrás, composto por concessionárias estatais, ao promover investimentos, reafirma a função do Estado de prover as condições necessárias para o desenvolvimento sustentado da economia brasileira, com vistas a promover o bem estar social.

Nesse contexto, cabe ressaltar a importância da continuidade da participação do Estado, seja como produtor direto, seja como regulador das atividades empresariais, para a concretização da eficiência alocativa e dinâmica no setor elétrico brasileiro.

Caberia à empresa pública o ajustamento da alocação de recursos, igualando o preço ao custo marginal (que reflete o custo de oportunidade de utilização de recursos para sua produção), com vistas a garantir um resultado socialmente desejado.

(Artigo recebido em janeiro de 2007. Versão final em março de 2007). 


\section{Notas}

1 CGTEE, CHESF, Eletronorte, Eletronuclear, Eletrosul, Furnas.

2 Como medida de elasticidade-renda foi utilizada a relação entre o índice de evolução do consumo de energia elétrica e o índice de evolução do PIB.

3 Earnings Before Interest, Taxes, Depreciation and Amortization

4 AES-SUL, AMPLA (antiga CERJ), BANDEIRANTE, BOA VISTA, CAIUÁ, CEAL, CEAM, CEB, CEEE, CELB, CELESC, CELG, CELPA, CELPE, CELTINS, CEMAT, CEMIG, CENF, CEPISA, CERON, CFLCL, CFLO, CNEE, COELBA, COELCE, COPEL, COSERN, CPFL Paulista, CPFL Piratininga, EEB, EEVP, ELEKTRO, ELETROACRE, ELETROPAULO, ENERGIPE, ENERSUL, ESCELSA, LIGHT, MANAUS ENERGIA, RGE, SAELPA.

5 AES - ELPA, AES - TIETÊ, CAT-LEO Energia S.A,. CEM (antiga Mercosul), CER, CESP, CLFSC, COCEL, CPFL Energia, CPFL Geração, CTEEP, DUKE - Geração Paranapanema, EMAE, EPP, INVESTCO, ITAPEBI, ITASA, TRACTEBEL (antiga Geralsul), VBC Energia (antiga Serramesa).

6 Deslocamento dos investimentos em função dos gastos públicos.

7 Receitas - impostos indiretos - despesas operacionais + depreciação do capital imobilizado

\section{Referências bibliográficas}

Alves, L.C.S.; Almeida, D. R.. Determinantes do investimento e expansão sustentada do Setor Elétrico Brasileiro - histórico recente e tendências. apresentado no XVII SNPTEE. Uberlândia, Minas Gerais: 2003.

Biderman, C.; Arvate, P.. Economia do setor público. Rio de Janeiro: Elsevier, 2004.

FAgundes, J.. Políticas de defesa da concorrência e política industrial: convergência ou divergência?. Revista do IBRAC, v.5, nº 6. 1998.

Grijó, E. Elementos do debate econômico da regulação. AGERGS, Revista Marco Regulatório, $\mathrm{n}^{\circ} 4,1^{\circ}$ semestre/2001.

Losekann, L. D. Reestruturação do Setor Elétrico Brasileiro: coordenação e concorrência. (Tese de Doutoramento). COPPE. Dez. 2003.

Melo, G. M.; Rodrigues Jr.. Determinantes do investimento privado no Brasil: 1970/1995. Brasília: IPEA, 1998 (Texto para Discussão n 605)

PINTO JR., H.Q.; Silveira, J.P.. Elementos da regulação setorial e de defesa da concorrência: uma agenda de questões para o Setor de Energia. ANP. (Nota Técnica n 006) maio/1999. Possas, M.; Fagundes, J.; Pondé, J.. Defesa da concorrência e regulação de setores de infraestrutura em transição. Artigo aprovado para a ANPEC. Dezembro, 1998.

GonçALVES, R. Lula na China: a periferia da periferia. UERJ - Laboratório de Políticas Públicas, 2004. Disponível em: <http://www.lpp-uerj.net/outrobrasil/ Referencias_Destaque.asp?Id_Sub_Referencia=15>. Acesso em: 7 mar.2007. 
Santacruz, R.. Defesa da concorrência. Rio de Janeiro: FGV Management - Cursos de Educação Continuada. p. 52, 2002.

SILVA, F. R.. A empresa pública e a intervenção do Estado na economia: ação suplementar à iniciativa privada - perspectivas em face da conjuntura atual. In: A empresa pública no Brasil: uma abordagem interdisciplinar. IPEA. Coletâneas de Monografias. Brasília: 1980. SchneIder, Carlos Rodolfo. Mercado livre de energia subsidia os grandes. In: Valor Econômico. 8 jun. 2006.

SteIndL, J.. Maturidade e estagnação no capitalismo americano. São Paulo. Abril Cultural. 1983. Stiglitz, J.E.. Economics of public sector. New York: W.W.Norton, 2000.

Tavares, M. C.. Acumulação de capital e industrialização no Brasil. Campinas, 1998.

Toscano, F. A eficiência produtiva e a eficácia alocativa. fev. 2003. Disponível em: <http:// www.portalbrasil.net/economia_colunista_2003_fev.htm>. Acesso em: 7 mar.2007. 


\section{Resumo - Resumen - Abstract}

\section{Análise da alocação de investimentos de empresas privadas e públicas no setor elétrico brasileiro \\ Denizart do Rosário Almeida e Andréa Costa Amâncio Negrão}

Este trabalho analisa a alocação de recursos de empresas públicas e privadas do setor elétrico brasileiro no período de 1995-2005 e a contribuição das estratégias de investimentos dessas empresas para o crescimento sustentado do setor. Para tanto, primeiramente, avalia-se a evolução da tarifa média de energia frente aos diferentes índices de preços da economia e seus possíveis reflexos sobre o consumo de energia e sobre os resultados financeiros das empresas.

Em seguida, analisa-se o comportamento dos investimentos realizados pelas empresas públicas e privadas no setor elétrico ao longo do período observado, tomando como referência dois modelos de determinação de investimento, em diferentes contextos. $O$ trabalho aponta a necessidade de continuidade da participação da empresa pública no novo modelo regulatório do setor elétrico brasileiro, que desempenha papel importante no ajustamento da alocação de recursos, com vistas a promover o desenvolvimento sustentado do setor elétrico brasileiro.

Palavras chave: investimento, setor elétrico, empresa pública

El análisis de la alocación de los recursos en empresas publicas y privadas en el sector eléctrico brasileño

Denizart do Rosário Almeida y Andréa Costa Amâncio Negrão

Este texto analiza la alocación de recursos en empresas públicas y privadas del sector eléctrico brasileño, en el período de 1995-2005, y la contribución de las estrategias de inversiones de esas empresas para el crecimiento sostenido del sector. Primeramente, examina la evolución de la tarifa promedia de la energía eléctrica frente a los diferentes índices de precios de la economía y sus posibles reflejos sobre el consumo de energía y los resultados financieros de las empresas. A continuación, se observa e

1 comportamiento de las inversiones realizadas por las empresas públicas y privadas del sector en el periodo, teniendo como referencia dos modelos de determinación de inversiones en diferentes contextos. El texto destaca la necesitad de asegurar la continuidad de la participación de las empresas públicas en el nuevo modelo regulatorio del sector eléctrico brasileño, que desempeñan un importante rol en el ajustamiento de la alocación de recursos para la promoción el desarrollo sostenido del sector.

Palabras clave: recursos, sector eléctrico, empresas públicas y privadas

\section{Analysis of investment allocation within state and private companies of the Brazilian electric power sector \\ Denizart do Rosário Almeida and Andréa Costa Amâncio Negrão}

This paper examines the allocation of resources within the state-owned and the private enterprises that structure the Brazilian electric power sector during 1995-2005, as well as the contribution of their investment strategies to the sustained development of the sector. In the first part, the article provides an assessment of the evolution of the average energy tariff compared against the different price indexes of the economy and its possible impacts on energy consumption and on the companies' financial results. It then analyzes the investment behavior of state and private companies in the electric power sector during the period by referring to two models of investment determination in 
different contexts. The paper points out that state-owned enterprises are still needed in the new regulatory model and stresses the important role they play in adjusting the allocation of resources in order to promote sustained development in the Brazilian electric power sector.

Keywords: investment, electric power sector, state company

Denizart do Rosário Almeida

Doutor em economia pelo Instituto de Economia Industrial da Universidade Federal do Rio de Janeiro (UFRJ). Trabalha há mais de 30 anos na Eletrobrás e é professor adjunto da Faculdade de Economia da Universidade Federal Fluminense (UFF). Contato: <denidfj@eletrobras.com>.

Andréa Costa Amâncio Negrão

Mestre em economia pelo Instituto Brasileiro de Mercado de Capitais (IBMEC/RJ). Trabalhou no governo federal por cerca de dez anos, ocupando cargos técnicos no Ipea, na Secretaria de Acompanhamento Econômico/ MF e na Agência Nacional de Saúde Suplementar. Atualmente, é supervisora de negócios da Eletrobrás e professora assistente da Escola de Negócios da UniverCidade. Contato: <andrea@eletrobras.com>. 